Buston, H. W. \& King, E. J. (1951). J. gen. Microbiol. 5, 766-771.

\title{
Further Observations on the Sporulation of Chaetomium globosum
}

\author{
By H. W. BUSTON AND ELIZABETH J. KING \\ Biochemical Laboratories, Department of Botany, \\ Imperial College of Science and Technology, London, S.W.7
}

SUMMARY: Extracts of a strain of Aspergillus fumigatus stimulate fruiting of Chaetomium globosum, but the factor responsible is not identical with that present in jute extract. Hexose phosphates, although stimulating fruiting, do not account for the activity of the jute extract.

Buston \& Basu (1948) reported the presence in extracts of jute of a substance which markedly stimulated perithecial formation of Chaetomium globosum Kunze, and showed that the stimulant was not identical with any of the recognized members of the vitamin B complex. Later, Basu (1951) found that the effect was in part due to the presence of calcium in the extracts. Buston \& Basu (1948) also examined the influence of a number of other micro-organisms grown in association with $C$. globosum, but in no case observed any stimulation of fruiting. Later, a chance contaminant of a plate culture of $C$. globosum was found markedly to promote sporulation, the organism responsible being identified as a strain of Aspergillus fumigatus Fresen. From cultures of this organism, extracts were obtained having an effect similar to that produced by the jute extract. The present work was undertaken in an attempt to characterize the active substances in the extracts, and, in view of the effect of certain sugar phosphates in accelerating fruiting of Melanospora destruens Shear (Hawker, 1948), to examine the effect of hexose phosphates on the sporulation of C. globosum.

\section{MATERIALS AND METHODS}

The strain of $C$. globosum was that, originally isolated by Basu from a piece of brown paper rotting in contact with moist soil, and designated by him No. 79 . The basal medium contained (per litre) $\mathrm{NaNO}_{3}, 2 \mathrm{~g}$.; $\mathrm{KH}_{2} \mathrm{PO}_{4}, 1 \mathrm{~g}$; $\mathrm{KCl}$, 0.5 g.; $\mathrm{MgSO}_{4} .7 \mathrm{H}_{2} \mathrm{O}, 0.5 \mathrm{~g}$; $\mathrm{FeSO}_{4} .7 \mathrm{H}_{2} \mathrm{O}, 0.01$ g. Glucose (British Drug Houses, Ltd., 'Analar'), 5 g./l. was the source of carbon unless otherwise stated. For solid media, agar (15 g./l.) was incorporated. Sterilization was at $10 \mathrm{lb}$./sq. in.; incubation was at $30^{\circ}$.

Jute extract. This was prepared from a recent sample of 'white' jute as described by Buston \& Basu (1948).

Extract of A. fumigatus. As a result of many experiments to discover the cultural conditions giving the best production of the fruiting factor the following method was used : 61 . of basal medium plus $0.5 \%$ sucrose and $0.1 \%$ malt extract in volumes of $500 \mathrm{ml}$. were inoculated with $A$. fumigatus and incubated at $28-30^{\circ}$ for 8 days. Both the staled medium and an extract of 
the mycelium were active, but since the former still contained growthpromoting substances derived from the malt extract, mycelial extracts were preferred as a source of the active factor. The best preparations were obtained by shaking the mycelium with $0.1 \mathrm{~N}-\mathrm{NaOH}$ in the presence of a little ether. The extract was neutralized with $\mathrm{HCl}$ before use.

\section{Attempted chemical characterization}

Attempts were made to concentrate the active material in jute extract by: precipitation with phosphotungstic acid or with barium hydroxide and ethanol; adsorption on Fuller's earth, alumina, magnesium oxide, calcium phosphate, Zeocarb, De-acidite, and activated charcoal at different $\mathrm{pH}$ values; extraction with ether, petroleum ether, chloroform, carbon tetrachloride, benzene, toluene, acetone, methanol, ethanol, and $n$-butanol. Partial success was obtained by adsorption on Norite at $\mathrm{pH} 2.5$ followed by elution with dilute $\mathrm{NaOH}$. The active substance was also partially dissolved by refluxing the dried jute extract with methanol, ethanol or $80 \%$ acetone. However, the active substance was almost always distributed between the various fractions and no method of precipitation, adsorption or extraction gave a reasonable promise of separation. Similar experiments with Aspergillus extract likewise gave unsatisfactory results, and the only partial concentration resulted from adsorption on Norite and elution with acetone.

Further experiments showed that the jute factor was quickly inactivated by hydrolysis for $30 \mathrm{~min}$. in the presence of $0.5 \mathrm{~N}-\mathrm{H}_{2} \mathrm{SO}_{4}$ or $0.6 \mathrm{~N}-\mathrm{NaOH}$, but that it was resistant to oxidation with $\mathrm{H}_{2} \mathrm{O}_{2}$ and to bromination in aqueous solution. Tests on the dried extract showed the presence of sulphur and phosphorus (see below), and absence of halogens and, surprisingly, nitrogen.

\section{The effect of hexose phosphates}

In view of the observation of Hawker (1948) that glucose-1-phosphate, fructose-1-6-diphosphate and certain other related compounds, when present in quite low concentrations $(0.05 \%)$ in media containing glucose or sucrose, favoured the fruiting of $\boldsymbol{M}$. destruens, the effect of these esters upon $C$. globosum was examined. When glucose or glucose +fructose was the source of carbon these phosphorylated compounds stimulated fruiting to an appreciable degree, but with sucrose their effect was hardly observable (Table 1). All sugar phosphates used, as well as those used by Hawker, were of biological origin, i.e. prepared enzymically from naturally-occurring materials. Thus the presence of associated growth or fruiting factors was not rigidly excluded and it could be argued that the effect of the phosphates used was due to some such impurity. To exclude this possibility a sample of glucose-1-phosphate was synthesized from bromoacetylglucose and silver phosphate (Cori, Colowick \& Cori, 1937), and was found to stimulate both growth and fruiting to a marked degree (Table 1). In further experiments hexose phosphates were used in an amount equivalent to $0.5 \%$ free hexose as the sole source of carbohydrate. Growth on glucose-1-phosphate was greater and fruiting more 
rapid than on the control $(0.5 \%$ glucose $)$, but the ester was no more effective under these conditions than when present only to the extent of $10 \%$ of the total carbohydrate. In each case fruiting occurred on the fourth or fifth day but growth was about twice as rapid on the all-ester medium. With fructose1-6-diphosphate as sole source of carbohydrate growth was abnormal, the colonies being large and spreading but very thin and almost of the starvation type. Fruiting occurred much earlier but perithecia appeared in a ring near the edge of the colony whereas they normally form first in the centre.

Table 1. Effect of hexose phosphates on grozth and sporulation of

C. globosum on agar media

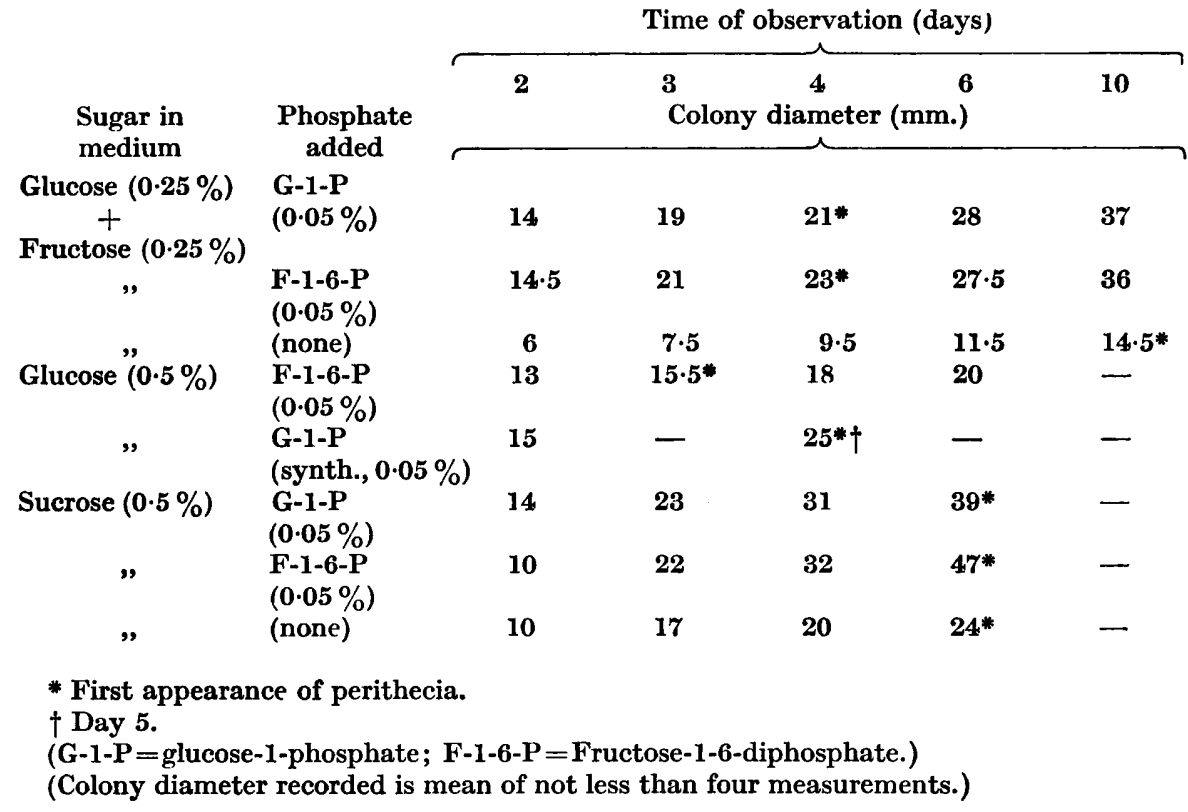

Comparison of jute extract, aspergillus extract and hexose phosphates

Since hexose phosphates possessed some activity it seemed desirable to ascertain whether the activity of the jute and the aspergillus extracts was due to the presence of such esters. Analyses of jute extract showed that the amount used contributed $0 \cdot 15 \mathrm{mg}$. total $\mathrm{P} / 100 \mathrm{ml}$. final medium; of this $0.08 \mathrm{mg}$. was inorganic and $\mathbf{0 . 0 4} \mathrm{mg}$. was 'acid-labile' (i.e. hydrolysed by $\mathrm{N}-\mathrm{HCl}$ at $100^{\circ}$, and considered to include glucose-1-phosphate and fructose1-6-diphosphate). From these results it was evident that the amount of ester phosphate derived from the jute extract was very small indeed. As a further test, jute and aspergillus extracts were hydrolysed under conditions known to destroy hexose phosphates, and the hydrolysates were tested for growth and fruiting activity. The results (Table 2) showed that jute extract after hydrolysis no longer stimulated fruiting, but that the aspergillus extract was much more resistant. 
Table 2. Effect of hydrolysis on the activity of jute and aspergillus extracts, as measured by colony diameter of $\mathrm{C}$. globosum on agar media $+0.5 \%$ glucose

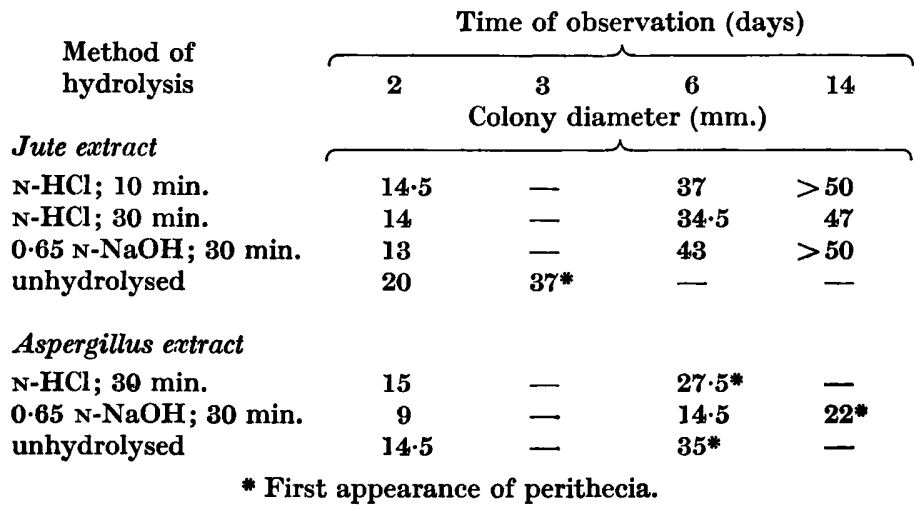

The activities of fructose diphosphate and of the two extracts were also compared by the cup method. Several plates of the medium plus $0.5 \%$ glucose and $2 \%$ agar were made and inoculated with a spore suspension of C. globosum. After incubation at $25^{\circ}$ for 5 days a cup was cut in each plate; sterile solutions of $1 \%$ fructose diphosphate, jute extract and aspergillus extract were placed in different cups. After 2 days at $25^{\circ}$ perithecia were observed in the colonies surrounding the cups of jute extract; after 4 to 5 days there was vigorous fruiting round the jute extract cups, rather less round the aspergillus extract and none round the fructose diphosphate.

\section{Note on the specific activity of sucrose}

Hawker \& Chaudhuri (1946) drew attention to the fact that sucrose seems more favourable than any other simple sugar to the rapid fruiting of $M$. destruens, probably because the rate of inversion in this case is sufficient to maintain an optimum level of hexose sugar. In the present work it has been noted that the favourable effect of glucose-1-phosphate is suppressed when sucrose forms the main carbohydrate supply. Since sucrose is readily obtained

Table 3. Effect of various samples of sucrose on growth and sporulation of $\mathrm{C}$. globosum on agar media containing $2 \%$ sucrose

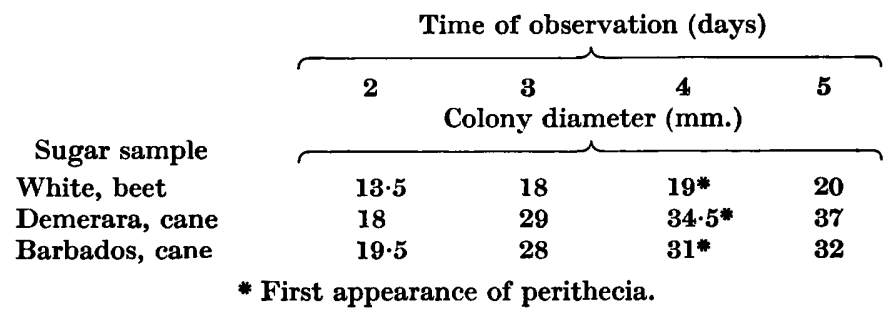


commercially in various degrees of refinement it seemed possible that tests on different grades of the sugar might indicate whether the activity could be ascribed to sucrose itself or to some contaminant. Refined white beet sugar, Demerara sugar, and moist brown (Barbados) sugar were used. The results (Table 3) showed that the activity of sucrose is indeed an intrinsic property of the sugar since fruiting occurred simultaneously and equally with all types. The cane sugars, however, evidently were contaminated with additional growth factors.

\section{DISCUSSION}

The prolonged attempts to separate or even to concentrate the factors present in jute extract and in $A$. fumigatus have led to little information concerning their chemical nature. Both are comparatively heat-stable in neutral solution but rapidly hydrolysed by alkali. The fact that neither is precipitated by phosphotungstic acid seems to rule out a basic substance and in fact the preferential extraction of the aspergillus factor with weak alkali indicates acidic properties. The absence of nitrogen from jute extract excludes many types of substance. The two extracts differ notably in the effect of acid hydrolysis which rapidly destroys the jute factor while under similar conditions aspergillus extract is but little affected. Differences in solubility were also noted, and it seems, therefore, that more than one substance is capable of producing the fruiting response in $C$. globosum. Basu (1947) suggested that during normal development there is a slow production of some compound within the organism which, on reaching a critical concentration, initiates fruiting. If the jute and the aspergillus factors are different the latter seems more likely to resemble the supposed intrinsic factor of C. globosum. Indeed, it might be considered remarkable if the jute plant produced a substance identical with that present in $C$. globosum unless the supposed substance were one of wide biochemical significance, playing a part in the metabolism of both micro-organisms and higher plants. Such substances are known and notable among them are the group of phosphorylated compounds derived from hexoses, two at least of which have been shown to assist fruiting of $C$. globosum. The comparative stability of the aspergillus factor towards acid hydrolysis shows that it is not one of the ordinary sugar phosphates (with the possible exception of the rather more stable glucose-6-phosphate), but in the case of the jute factor the behaviour on hydrolysis does not exclude the possibility that a sugar phosphate may be mainly responsible for its activity. The total amount of phosphorus introduced by the jute extract was $0 \cdot 15$ $\mathrm{mg} . / 100 \mathrm{ml}$. medium, and of this $0.04 \mathrm{mg}$. was acid-labile organic phosphorus (glucose-1-phosphate and fructose-1-6-diphosphate). Calculated as glucose1-phosphate, this represents approximately $0.35 \mathrm{mg}$. ester $/ 100 \mathrm{ml}$. medium; since this is so much less than the amount $(50 \mathrm{mg} . / 100 \mathrm{ml}$.) found to give a good response, it seems unlikely that the effect of the jute extract can be ascribed entirely to the presence of hexose phosphates.

Basu (1950) found that calcium in a limited range of concentrations (c. 10 p.p.m.) reproduces to some extent the effect of jute extract, but although 
we agree that the ash of jute does stimulate fruiting, the susceptibility of the extract to acid hydrolysis does not support the view that the calcium ion as such is responsible for its activity. The conclusion is reached that if calcium plays a part in the fruiting mechanism, and that if, as seems likely, organic phosphates are involved, neither can account entirely for the properties of extracts of jute and of $A$. fumigatus.

One of us (E. J. K.) wishes to thank the Committee of the Indian Jute Mills Association Research Institute for financial support. We also wish to record our thanks to Dr S. N. Basu and Dr L. E. Hawker for useful discussion, and to Miss J. Bishop for valuable technical assistance.

\section{REFERENCES}

BaSU, S. N. (1947). On the sporulation of Chaetomium globosum. Thesis, University of London.

BASU, S. N. (1951). Significance of calcium in the fruiting of Chaetomium species. J. gen. Microbiol. 5, 231.

Buston, H. W. \& Basu, S. N. (1948). Some factors affecting the growth and sporulation of Chaetomium globosum and Memnoniella echinata. J. gen. Microbiol. 2, 162.

Cori, C. F., Colowick, S. P. \& Cori, G. T. (1937). The isolation and synthesis of glucose-1-phosphoric acid. J. biol. Chem. 121, 465.

HAwkER, L. E. (1948). Stimulation of the formation of perithecia of $M$. destruens Shear by small quantities of certain phosphoric esters of glucose and fructose. Ann. Bot., Lond. N.S., 12, 77.

Hawker, L. E. \& Chaudhuri, S. D. (1946). Growth and fruiting of certain ascomycetous fungi as influenced by the nature and concentration of carbohydrate in the medium. Ann. Bot., Lond. N.S., 10, 185.

(Received 27 October 1950) 